\title{
Innovative solutions for recycling and waste disposal and labour market in Russia
}

\author{
Marina Danilina ${ }^{1,2,3,4,}$, Ekaterina $\mathrm{Kravetz}^{5}$, Andrey Brilon $^{6}$, Irina Astafieva ${ }^{7}$, Vadim \\ Blekus $^{7}$, Lydia Shirokova ${ }^{7}$, and Samvel Doholyan ${ }^{8}$ \\ ${ }^{1}$ Moscow University named after S.Yu. Vitte (MUIV), $2^{\text {nd }}$ Kozhukhovsky proezd, 12, stroyeniye 1, \\ 115432, Moscow, Russia \\ ${ }^{2}$ Research Institute VNII of Labor, Ministry of Labour of Russia, Zemlyanoy Val, 34, 105064 \\ Moscow, Russia \\ ${ }^{3}$ Plekhanov Russian University of Economics (PRUE), Stremyanny per., 36, 117997 Moscow, Russia \\ ${ }^{4}$ Finance University under the Government of the Russian Federation, Leningradsky prosp., 49, \\ 125993 Moscow, Russia \\ ${ }^{5}$ Technological University, ul. Chechulina, 14, Moscow, Russia \\ ${ }^{6}$ Russian University of Cooperation, 117997, Mitishi, Russia \\ ${ }^{7}$ Gzel'skii State University, posiolok Elektroizoliator, 67, Russia \\ ${ }^{8}$ Russian State University for the Humanities, Moscow and Moscow City Pedagogical University, \\ Moscow, Russia
}

\begin{abstract}
In the modern society the activities related to solving environmental and economic problems, managing climate change, reducing greenhouse gas emissions, resource and energy conservation, consumption of irreplaceable resources are of great importance. To effectively manage waste and increase the share of secondary raw materials that go for processing, it is necessary to automate processes and use IT technologies at all stages: during collection, accumulation, logistics and processing. On the basis of the content analysis method the authors analyse the application of the recycling and waste disposal and present the future trends and the advantages of their application in Russia. The severity of the environmental impact of waste treatment and disposal depends on the volume of waste generated, its composition, the amount of illegally buried waste, the amount of waste disposed of in a landfill and the standards of waste treatment plants. The future impact of the waste management process will depend on how these factors change. Waste final treatment today means either landfill or incineration, and these two types of final treatment have different, but in both cases, negative impact on the environment.
\end{abstract}

\section{Introduction}

One of the areas of innovation in modern society is activities related to solving environmental and economic problems, managing climate change, reducing greenhouse gas emissions, resource and energy conservation, consumption of irreplaceable resources. An

\footnotetext{
${ }^{*}$ Corresponding author: marinadanilina@yandex.ru
} 
example of the implementation of this approach is the development and implementation of new innovative technologies in the field of waste processing and recycling. This approach is economically profitable, since the involvement of secondary resources in the economic turnover as a resource base for production can significantly reduce the economic costs of production. At the same time, the tasks of improving the environment, saving natural resources, energy, and preserving natural capital are being solved.

In Russia, 60 million tons of solid household waste are generated annually. Of these, $40-60 \%$ are valuable raw materials suitable for processing, but in fact only $5 \%$ is processed. The remaining volumes are almost completely sent to landfills, there are about 15 thousand of them in Russia, and landfills, there are about 17 thousand of them. An insignificant part ends up in incinerators, there are ten of them in Russia. The area of landfills and landfills in our country is more than 4 million hectares - slightly less than the area of the Netherlands.

To effectively manage waste and increase the share of secondary raw materials that go for processing, it is necessary to automate processes and use IT technologies at all stages: during collection, accumulation, logistics and processing.

\section{Materials and methods}

On the basis of the content analysis method the authors analyse the application of the recycling and waste disposal in Russia.

IT solutions at the stage of waste collection and accumulation.

For efficient collection and accumulation of waste, there are several automated solutions: fandomats, bins with automatic sorting by fractions and pressing of raw materials at the collection point.

Fandomats are automatic machines for receiving secondary raw materials, they are also called reverse vending machines. Most often they provide a reward for the recyclable person. Fandomats mainly collect PET bottles and aluminum cans. Their advantage is that raw materials can be obtained in the purest and most suitable form for processing. Fandomats are often installed in popular public places with high traffic - shops and shopping centers, this helps to involve more people in the separate waste collection process.

Tomra is one of the world leaders and pioneers in fandom production.

Pandomat is one of the first importers of such devices to the territory of Russia. Innovative Ecological Platform is the first Russian manufacturer of fandomats. Bins with automatic sorting by fractions recognize the composition of secondary raw materials using artificial intelligence, sort, press and control the filling level. Bin-e is a European manufacturer of smart waste bins. SmartCity Bin is a Russian development of a waste bin that compresses waste with garbage collection control, it works completely autonomously on solar panels.

IT solutions at the waste disposal stage [1,2].

There are solutions for monitoring the filling of garbage containers and managing the logistics of exporting companies both in the foreign and in the Russian market.

IT solution for waste disposal companies. Sensors determine the level of fullness of containers, predict the time when export will be required, and special software optimizes logistics. Enevo is an American company with branches in Europe that provides similar IT solutions. Wasteout is a Russian analogue (offers a reduction in operating costs from 20 to $50 \%)$.

The Big Three is a solution for modeling the movement of all waste in the region. Helps Russian municipalities develop territorial waste management schemes. Provides regional operators with software for managing a garbage truck fleet. Company representatives on social networks mentioned that they are developing occupancy sensors [1,2].

IT solutions at the logistics stage. 
"Cleaner" is a Russian online platform focused on b2b clients. It brings together customers who need the removal of secondary raw materials and carriers who are ready to take orders. Due to the automation of processes, its own TMS (logistics management system) and a large number of drivers connected to the service, the platform ensures the timely removal of secondary raw materials even in small volumes from $50 \mathrm{~kg}$, provides closing documents and acts for environmental reporting. Similar services in the USA are Rubicon, Trash Warrior.

IT solutions at the waste processing stage.

We are talking primarily about automated solutions for industrial waste sorting. There are no such technologies in Russia yet, but there are several solutions in the foreign market.

Zen Robotics - use machine vision to identify different types of materials and separate them on a conveyor belt. The separation process is carried out by a robot arm - this solution works better with large, non-shredded waste.

Tomra uses spectral sensors to detect the type of material and separate them on the conveyor. The separation process takes place by a pneumatic mechanism: particles of different types of waste are shot off by air streams at different distances, due to which objects are separated in the space between different containers.

There are several online platforms for the purchase and sale of recyclable materials on the Russian market: Plastinfo, Reactor, Waste Exchange, ROSHLAM.RU. Eat me is a food sharing service that prevents food that has not yet been spoiled from ending up in landfills.

The number of workers in the processing of secondary raw materials, according to statistical data, amounted to 4.2 thousand people (officially registered employees), of which $97 \%$ was engaged in the processing of metal waste and scrap. Average monthly nominal accrued wages of employees amounted to 28 thousand rubles in 2016, having increased by compared with 2015 by $9 \%$. At the same time, there are peculiarities of employment in the "garbage" sphere, distorting statistics (associated with the "gray hiring" of people who do not have the opportunity to find a job officially, as well as with "economic inexpediency" legally formalize this business - in the opinion of the entrepreneurs themselves, of course) $[1,2]$.

The rapid development of industry and technology has led to the fact that the issue of environmental protection today is one of the most urgent and urgent. Humanity is increasingly faced with environmental problems, for the solution of which it is necessary to modernize a variety of activities: from production and construction to education and enlightenment. This can be done by specialists with fundamentally new interdisciplinary knowledge and competencies. Their demand in the labour market is growing every year.

The industry of recycling polymers and plastics is actively developing, which are then reused. The recycling technologist is engaged in the development of new technologies for the repeated use of raw materials, as well as the introduction of algorithms for waste-free production in industry. The functionality of such a specialist depends on the industry. For example, an eco-recycler in metallurgy is responsible for reducing gaseous emissions in metallurgical plants. He selects gas cleaning devices for them, is engaged in the reclamation of dumps, the introduction of the principles of environmentally friendly production and the reduction of emissions and waste of metallurgy in general. This direction is new for the Russian market. Nevertheless, today there are 13 training programs in universities that can become the basis for a profession.

Waste management engineer organizes the collection, use, disposal, transportation and disposal of waste. The main goal of his work is to protect the environment and people from the harmful effects of production and consumption waste, as well as to improve the sanitary condition and the appearance of cities. It is now possible to obtain basic knowledge for working in a profession at 87 universities. 
The main task of the Systems Biotechnologist - search and replacement of outdated solutions in various fields with new products from the field of biotechnology. For example, a systems biotechnologist is helping transportation companies switch to biofuels and eliminating diesel engines, and construction companies using new biomaterials instead of cement and concrete. Today, access to the profession allows you to get 25 programs in 66 universities in Russia.

\section{Results}

Due to the rapid development of industrial production, mankind is faced with the need to use new technologies for waste disposal. Today in Russia about $94 \%$ of garbage is simply left at special landfills. In Europe, this figure also leaves much to be desired, albeit much less $(40 \%)$.

Incineration. This relatively new technology in waste processing can be considered as sufficiently effective only if a number of mandatory conditions are met. So, for its implementation, it will be necessary to have incineration plants equipped with the latest technology. The construction of such enterprises usually takes a lot of money and time (over 5 years). Garbage must be sorted before starting the process. Batteries and metal and plastic components are removed from the total mass.

International research organizations note a number of objective advantages of this method at once, namely: Almost complete absence of unpleasant odors. A small proportion of toxic substances released into the atmosphere. Research by the Waste Management magazine has proven that incineration causes only $3.4 \mathrm{~g}$ of dioxins to be released into the air each year, compared to the 1300 that occurs in landfills. The organization "UK Environmental Services Association" has established that the technology does not cause mutations in plants grown near processing plants, and also does not provoke tumor diseases and ailments of the respiratory system in humans.

Possibility of obtaining a powerful thermal and energy resource base. This turns out to be especially relevant when using pyrolysis, a technology in which the combination of low or high temperatures (from 450 to $900^{\circ}$ or more than $900^{\circ}$, respectively) with an insufficient amount of oxygen does not lead to the release of harmful and toxic substances, but to the decomposition of the object into its constituent elements [3, 4].

In Russia, this method is still at the stage of development and experimental verification. It is assumed that the introduction of pyrolysis in constant practice will provide heat to entire cities with a population of 300,000 people. The enterprises themselves will be able to serve residents for 20 years with an average payback period of 4 years. They also do not have to be supplied with energy to function, because the synthesis gas generated as a result of combustion will become the fuel for the reactors [3,4].

Incineration of garbage also allows not to form many kilometers of heap, to which birds and rodents - carriers of infection and viruses - gather from the surrounding territories. However, this method requires mandatory disposal of ash in special storages due to the fact that, containing some impurities of heavy metals, dioxins and mercury, it cannot be simply dispersed or left on the ground.

Plasma Recycling. The next new recycling technology is one of the safest and most innovative solutions that could be found in this matter. It also uses the principle of processing the mass with high temperatures, but the litter is brought not to decomposition, but to transformation into a gas.

In this state, the former objects are distilled into steam, due to which several useful resources are obtained at once: electricity; environmentally friendly slag; non-pyrolyzable residues that can be reused for industrial purposes. 
Backfilling. Among the technologies for waste disposal, you can find those that are used not so much because of obvious positive criteria, but because of economic benefits. A striking example of a new method of this kind is the backfilling of a solid waste landfill, which results in the formation of gas synthesis - methane, carbon dioxide, nitrogen, hydrogen, hydrogen sulfide and oxygen. In other words, the landfill is not just left on the planet's surface for years, but is buried under a layer of earth and clay for 10-30 years. Over time, a non-hazardous natural landfill gas is produced, which is then used to produce fuel, steam, heat and electricity.

Composting. The latest new technology for recycling household waste is excellent for organic materials - food residues, vegetation, paper. This method of disposal, not used in large-scale industry, is a favorite among summer residents and farmers. The composting process consists in the formation of special piles of different sizes, which are regularly turned over (daily, once a month, once a year, etc., depending on the person's wishes for the duration of composting).

\section{Discussions}

Humanity has been recycling waste since ancient times. In particular, in agriculture, it has always been widely practiced to reuse organic waste obtained in the process of agricultural and domestic activities.

Since the second half of the 20th century, waste recycling has come to be seen as one of the means of combating environmental pollution and rational use of natural resources and energy. The state plays a key role in the field of waste recycling, providing the necessary legal framework and supervision over the implementation of laws that establish requirements for the production, operation and disposal of products and waste management, as well as create favorable conditions for the development and implementation of resourcesaving technologies and practices $[5,6]$.

In order to reduce the cost of products using waste, tax incentives have been introduced. To attract investment in the creation of waste processing facilities, a system of soft loans has been created, including partially reimbursed and gratuitous in case of unsuccessful decisions. In order to stimulate the demand for products using waste in a number of countries, restrictions are imposed on the consumption of products manufactured without using waste, and the scale of the use of the system of city and municipal orders for products from waste is increasing.

Environmental payments are widespread in many countries to reimburse the costs of collecting and pre-processing a number of the most common types of products that create typical problems with their disposal after use - batteries, lubricating oils, accumulators, worn tires. Payments for the use of packaging or license fees for the use of the Green Point trademark are especially widespread, at the expense of which the collection and processing of packaging waste is organized.

The efforts of foreign countries to collect and process waste are coordinated at the international level. Thus, for the EU countries, the Fifth Action Program on Environmental Protection for 1992-2000 was prepared, within the framework of which the following requirements were established $[5,6]$ :

- the obligatory existence in the EU countries of plans for waste treatment and the creation of a market for secondary raw materials;

- rationing the level of use of the most common waste (for waste paper, glass and plastic packaging, the level of collection and recycling in 2000 was set at 50\%).

The system of state regulation of solving the problem of waste recycling in the EU countries continues to improve. The main provisions of a new strategy for creating an economically and financially sustainable waste management system are formulated. Key 
principles of this strategy include: maintaining a balance of economic and environmental interests; coordinated use of economic and administrative instruments; stimulating investment in waste recycling; introduction of mechanisms for tax incentives, loans and government subsidies aimed at expanding the production and technological base of waste processing.

Particular shifts are taking place in the international coordination of the organization of collection and recycling of packaging waste. It was under the control of state bodies, mainly in the 90s, that centrally controlled national systems for the collection and processing of waste were intensively created, functioning with financial support from environmental payments for the use of packaging or from license fees for using the Green Point trademark, that is without attracting state budget funds.

In 1994, a special EU Directive No. 62 "On packaging and packaging waste" was put into effect, obliging the EU countries to create organizational, regulatory and economic conditions for the collection and recycling of used packaging. Relevant milestones have been established for the level of processing of such waste. In particular, in accordance with the requirements of this Directive, EU countries must ensure that $50-65 \%$ of packaging waste is recycled within 5 years after acceding to this Directive. By the beginning of 2002, 17 EU countries had joined this directive, including Germany, France, Sweden, Norway, Austria, Spain, etc. [5, 6].

For Moscow, as for the largest metropolis, the issue of using innovative ecotechnologies is topical. The projects that the metropolitan companies will present at the forum have high potential for implementation in the urban environment and improvement of the waste management system. There is a demand for advanced solutions in this area on the part of Muscovites, who are moving towards conscious consumption and sorting of waste. Business is also interested in this: enterprises are increasingly focusing on trends in sustainable development and environmentally friendly production.

\section{Conclusion}

To conclude, in the coming years, the digital transformation in the global garbage market will develop in several directions: urban infrastructure will see many innovations within the framework of smart city and IoT concepts, such as PaaS (Platform as a Service) - a combination of an application platform with managed cloud infrastructure services, as well as SaaS (Software as a Service). Classic waste recycling and IT companies are planning joint projects. More than 50 major technology brands are already developing IT solutions in the global garbage market. The Cleaner team is building an ecosystem of digital services that will accompany the movement of waste at all stages. In the coming years, the following will be launched:

-a system of accounting and management of production and procurement enterprises (collection points where recyclable materials are pressed and accumulated for further sale to processing plants);

-payment platform for collecting recyclable materials from individuals;

-an online platform that brings together producers and processors to implement extended producer responsibility.

The severity of the environmental impact of waste treatment and disposal depends on the volume of waste generated, its composition, the amount of illegally buried waste, the amount of waste disposed of in a landfill and the standards of waste treatment plants. The future impact of the waste management process will depend on how these factors change. Waste final treatment today means either landfill or incineration, and these two types of final treatment have different, but in both cases, negative impact on the environment. 


\section{References}

1. Energy Management, A comprehensive guide to controlling energy use, Carbon Trust (2013)

2. D. Rodrik, C. Sabel, Industrial Policy for the Twenty-First Century (2004) http://www.vedegylet.hu/fejkrit/szvggyujt/rodrik_industrial_policy.pdf

3. D.O. Skobelev, Environmental Industrial Policy In Russia: Economic, Resource Efficiency And Environmental Aspects, International Multidisciplinary Scientific GeoConference SGEM 19, 5.3, 291-298 (2019)

4. CEFIC: Facts and Figures of the European Chemical Industry, https://cefic.org/app/uploads/2018/12/Cefic_FactsAnd_Figures_2018_Industrial_BRC HURE_TRADE.pdf

5. T. Guseva, et al. Integrated Pollution Prevention and Control: Current Practices and Prospects for the Development in Russia, Proceedings of the International Multidisciplinary Scientific GeoConference Surveying Geology and Mining Ecology Management, SGEM 14, 391-398 (2014)

6. T.V. Guseva, K.A. Shchelchkov, A.Yu. Sanzharovsky, Ya.P. Molchanova, Best Available Techniques, Energy Efficiency Enhancement and Carbon Emissions Reduction, International Multidisciplinary Scientific GeoConference SGEM 19, 5.1, 63-70 (2019) 